\title{
Teoría de la Historia, conciencia histórica e historia conceptual: una conversación con Javier Fernández Sebastián
}

\section{Theory of History, Historical Consciousness and Conceptual History: A Conversation with Javier Fernández Sebastián}

\author{
Daniel Ovalle Pastén \\ Universidad Adolfo Ibáñez \\ Universidad Andrés Bello, Chile \\ ovalle.daniel@gmail.com
}

\section{Resumen}

Este trabajo presenta una entrevista académica al profesor Javier Fernández Sebastián realizada en el contexto del XVIII Congreso AHILA, Valencia 2017. Las preguntas están orientadas hacia sus preocupaciones actuales acerca de la teoría de la historia -lugar donde Fernández observa un rechazo al trabajo teórico por parte de la academia-, la relación teoría e historia conceptual y al problema de la temporalidad, este último desde la problemática de la conciencia histórica. La entrevista tiene como objetivo sumar discusión a la necesidad del trabajo teórico de la escritura de la historia.

\section{Palabras claves}

Teoría de la historia, historia conceptual, conciencia histórica, temporalidad.

\begin{abstract}
This piece deals with an academic interview with Professor Javier Fernández Sebastián conducted in the context of the XVIII AHILA Congress, Valencia 2017. The questions are oriented towards his current concerns about the theory of history - a place where Fernández observes a rejection of the theoretical work by the academy -, the relationship between theory and conceptual history, and the problem of temporality, the latter from the problem of historical consciousness. The objective of the interview is to add discussion to the need for the theoretical work in writing history.
\end{abstract}

Keywords

Theory of history, conceptual history, historical consciousness, temporality. 
Si hay un nombre entre los historiadores iberoamericanos contemporáneos que se repite es el de Javier Fernández Sebastián (Madrid, 1952), referencia obligada desde la Historia Intelectual, la Semántica Histórica y la Teoría de la Historia. Tres razones que ameritaban una entrevista y su publicación en una revista especializada. La posibilidad se dio en el marco del XVIII Congreso AHILA (Valencia, septiembre del 2017), dentro del simposio número 61 "Lo marginal en el centro: nuevos caminos de la historiografía actual", donde el profesor dictó una clase magistral y el entrevistador fue parte de los conferencistas. Agradezco la disponibilidad del profesor Fernández para la entrevista y su buena voluntad en el proceso de redacción.

Fernández Sebastián es profesor de Historia del Pensamiento y de los Movimientos Sociales y Políticos en la Universidad del País Vasco-Euskal Herriko Unibertsitatea (Bilbao). Ha sido profesor e investigador invitado, entre otros, en los siguientes centros de estudios: Escuela de Altos Estudios de París, MaxPlanck Institut für Geschichte, Universidad de Cambridge, Universidad Sorbonne Nouvelle (Paris III), Universidad de São Paulo, Universidad de Timisora y Universidad de Harvard.

Destaca por dirigir uno de los proyectos más importantes en nuestra lengua sobre historia conceptual, Iberconceptos: Proyecto Iberoamericano de Historia Conceptual, integrado por más de un centenar de especialistas de la región. Dicho proyecto ha devenido en una serie de publicaciones de libros y dossiers, destacando el Diccionario político y social del mundo iberoamericano. La era de las revoluciones, 1750-1850 (tomo I, 2009) y los diez volúmenes del Diccionario político y social del mundo iberoamericano (tomo II, 2014), donde Fernández Sebastián figura como Director de cada uno de los volúmenes. A la vez, nuestro autor es investigador principal del Grupo de Investigación en Historia Intelectual de la Política Moderna. Lenguajes, conceptos, discursos. Equipo que trabaja a la vez con otras redes, tales como el mismo Iberconceptos, el History of Political and Social Concepts Group (HPSCG) y el European Conceptual History Proyect. Este último proyecta la publicación de cinco volúmenes de temáticas de historia conceptual europea, donde ya ha visto la luz Conceptual History in the European Space, editado por Fernández Sebastián en conjunto con Michael Freeden y Willibald Steinmetz por la editorial Berghahn (2017). Tales pergaminos hablan por sí solos, pero no son los únicos.

El profesor ha editado una serie de libros y escrito artículos de alto impacto, ${ }^{1}$ destacando, por ejemplo, el libro publicado junto a Joëlle Chassin L'avènement de l'opinion publique: Europe et Amérique XVIII-XIXe siècles, (París, L'Harmattan, 2004) y Political Concepts and Time. New Approaches to Conceptual History (Santander, Cantabria University Press/McGraw-Hill Interamericana de España, 2011).

\footnotetext{
${ }^{1}$ Para un conocimiento en detalle de sus publicaciones, el lector interesado puede consultar la siguiente dirección web: http://www.javierfsebastian.com/
} 
Como se observa, los méritos de nuestro entrevistado no son escasos. Sirva esta entrevista para ahondar sobre sus temáticas de investigación. La entrevista académica se transforma así en una herramienta útil, en la medida que buenas preguntas ayudan a complejizar problemas de investigación que muchas veces los libros y artículos no permiten relacionar, además de actualizar el momento del intelectual y sus intereses desde la reflexión abierta.

\section{1) Estimado profesor, ¿nos podría contar cómo llegó al trabajo teórico en la disciplina histórica?}

Javier Fernández Sebastián: Yo diría que he llegado por dos caminos diferentes. Por una parte, mi docencia se centra desde hace muchos años en historia intelectual y del pensamiento político, y para mí la historiografía es una parte sustancial de la historia intelectual. La historia intelectual abarca una gran cantidad de historias parciales, sectoriales, y una de ellas es la historia de la historiografía y del pensamiento historiográfico, que desemboca de manera natural en el ámbito teórico. Por otro lado, quizás la vía más directa por donde he llegado a la teoría es a través de la propia historia conceptual. La lectura de historiadores clásicos, incluyendo a Koselleck, y de filósofos como Gadamer me llevó a preguntarme por la lingüísticidad y la historicidad del mundo en que vivimos. Cuando empiezas a plantearte seriamente preguntas sobre el carácter histórico del lenguaje, ese cuestionamiento te lleva a la historización de las categorías del análisis histórico. La semántica histórica, en este sentido, se interesa por el subsuelo de la historiografía, un tipo de indagación que nos distancia críticamente de la visión del historiador ingenuo que utiliza de manera mecánica las herramientas que aprendió en la escuela donde se formó, esto es, sin reflexionar sobre su historicidad. Yo mismo fui durante algún tiempo uno de esos historiadores ingenuos, antes de tomar conciencia de que las herramientas analíticas que utilizamos han de ser pensadas y analizadas también históricamente. Entonces comencé a interesarme por cuestiones epistemológicas, lo que me llevó a leer filosofía analítica de la historia. Recuerdo que comencé leyendo a Arthur Danto y a Louis Mink, para pasar luego a otros autores tan distintos como Michel de Certeau o Paul Ricoeur. Creo en suma que de la historia conceptual a la teoría uno pasa casi sin darte cuenta; esa al menos ha sido mi experiencia personal. Y, según lo veo actualmente, un historiador, especialmente un historiador intelectual, no debería prescindir de la teoría de la historia.

\section{2) En una conferencia que dio en la Escuela de Verano "Concepta" en el Colegio de México en el año 2017, usted argumentó la necesidad de volver a pensar la "teoría de la historia". ¿Podría desarrollar este argumento?}

JFS.: A mi modo de ver, su pregunta tiene que ver con lo que podríamos llamar el giro histórico - aunque sé muy bien que hemos abusado de la palabra giro -, esto es, con un salto, una vuelta de tuerca adicional en la progresiva historización del mundo iniciada hace dos o tres siglos. La crisis del historicismo que estalló en el período de entreguerras puso de manifiesto que, paradójicamente, ni la escuela histórica alemana ni tampoco la 
hermenéutica de Dilthey eran suficientemente históricas. Los adeptos de ambas escuelas estaban convencidos de que, si el historiador/intérprete desarrollaba sus tareas con las técnicas y cautelas adecuadas, podía llegar a una interpretación definitiva de los textos históricos y a una clarificación de los sucesos a través de las fuentes de una vez y para siempre. Esa irrazonable presunción evidenciaba que el intérprete no se consideraba concernido por la propia historicidad, como si pudiera sustraerse a ella: la historia venía a ser una suerte de punto ciego para el historiador, que estaba dispuesto a historizarlo todo salvo la propia historia. Ahora bien, el giro histórico al que me refería al comienzo de mi respuesta, un giro de amplio radio que se ha ido efectuando paulatinamente a lo largo del siglo XX, radicaliza nuestra mirada histórica sobre las realidades fácticas e intelectuales (lenguaje incluido). Yo diría que la famosa "crisis de la historia" de los años ochenta y noventa y también el llamado giro lingüístico tienen que ver con ese proceso silencioso pero más profundo, quiero decir con la asunción por los historiadores del carácter inevitablemente histórico de su propio quehacer. Cuando el historiador cae en la cuenta de que no es el ojo de Dios, cuando toma conciencia de que tampoco él puede sustraerse a la corriente de la historia, empieza a verse a sí mismo como sujeto histórico (incluso como posible objeto de estudio en el futuro). Y, al constatar que tú también ocupas un lugar particular en el tiempo, y sobre todo que ese lugar no es necesariamente el momento supremo, el Aleph de todos los tiempos, eso te lleva a contemplar con humildad tu propio oficio desde una mirada histórico-teórica, y esa reflexión incluye la historización de tus categorías de análisis. Desde esta perspectiva renovada el historiador ya no se limita a historizar sus objetos habituales "externos" de estudio, sino que se abre también a la historización de su propio trabajo. Eso te hace prestar atención a la historiografía, pero no a una historiografía meramente descriptiva - que se limita a dar cuenta de lo que han publicado los historiadores -, sino a la historización de una serie de temas más profundos de los que se ocupa la teoría de la historia, incluyendo algo que en principio puede parecer tan inasible como la conciencia histórica. Desde este punto de vista, la teoría de la historia no es ni más ni menos que una reflexión sobre las bases epistemológicas de la historiografía. Puedes entrar alternativamente por la puerta de filosofía analítica o por la hermenéutica de Gadamer o de Ricoeur. Dos caminos que no son fácilmente compatibles. La teoría analítica y la hermenéutica son, en efecto, dos vías que apenas se tocan. El punto de cruce más evidente podría ser Wittgenstein, pero se trata de un problema complejo. Plantearse esta clase de cuestiones es hoy en día cada vez más frecuente por parte de aquellos historiadores que se interesan por la teoría/filosofía de la historia, aunque ya sabemos del desprestigio que arrastra la etiqueta "filosofía de la historia", que solemos asociar con autores como Hegel o Marx. Aunque yo diría que incluso esto - la definitiva obsolescencia de una filosofía sustantiva de la historia - hoy está siendo discutido. Algunos estudiosos jóvenes, especialmente en Alemania, han argumentado recientemente la pertinencia de retomar y renovar la filosofía de la historia (pienso por ejemplo en algunos trabajos de Zoltán Simon, quien ha tratado temáticas afines desde el prisma de la experiencia). $^{2}$

\footnotetext{
${ }^{2}$ Zoltán Boldizsár Simon, "History manifested: making sense of unprecedented change", European Review of History, 22, 5 (2015): 819-834; "The expression of historical experience", History and Theory, 54 (2015):
} 
3) ...y en España, ¿en qué estado cree que se encuentran los estudios dedicados a la "teoría de la historia"?

JFS.: Yo creo que en España la teoría de la historia no se ha trabajado suficientemente, sobre todo desde la historiografía. Si dejamos a un lado los ensayos de algunos filósofos, como es el caso de Manuel Cruz, y con algunas ilustres excepciones (como los libros de Miguel Ángel Cabrera), la mayor parte de las obras que se han publicado sobre estos temas escritas por historiadores lo fueron como resultado de un ejercicio académico-administrativo de reflexión sobre la materia que el sistema universitario exigía para el acceso a las cátedras de historia. Varios de estos trabajos (pienso en los libros de Julio Aróstegui, Elena Hernández Sandoica y varios más) vieron la luz en efecto como subproducto de ese ejercicio obligatorio del concurso/oposición a catedrático. Por otra parte, los trabajos teóricos más solventes relacionados con la filosofía de la historia provienen sobre todo de la filosofía, como área de conocimiento universitaria. En este punto - que cuenta en España con la poderosa tradición orteguiana [alusión a la obra historiológica de José Ortega y Gasset] - vienen a mi mente autores como el mencionado Manuel Cruz, José Luis Villacañas, Concha Roldán, Reyes Mate o Faustino Oncina. Es más, yo diría que por parte de los historiadores ha existido durante décadas una actitud deliberadamente anti-teórica (que todavía persiste en ciertos sectores), motivada en parte por una posición temerosa ante los "excesos teóricos" asociados a la postmodernidad, el posestructuralismo, el giro lingüístico, el deconstruccionismo, etc. Todo eso se condenó en bloque como anatema, arrojando el niño con el agua sucia. Por fortuna, creo que muchos de esos prejuicios y de esa fiebre antiteórica están hoy felizmente superados. En la actualidad, los historiadores españoles están mucho más abiertos al trabajo teórico. Y, desde luego, en lo personal creo que no debemos hacer dejación de esa responsabilidad y es insoslayable acercarnos a la teoría de la historia.

4) En su intervención magistral en el marco del XVIII Congreso de la Asociación de Historiadores Latinoamericanistas Europeos (AHILA), dedicado a la historiografía actual, usted mencionó -como ha hecho en otras ocasiones- que estaríamos en presencia de una nueva "conciencia histórica", coincidiendo con otros autores como François Hartog y Manuel Cruz, lo cual tendría efectos en la historiografía. ¿Cuáles serían esos efectos?

JFS.: A mi juicio actualmente se observan en este campo dos movimientos contradictorios. Por una parte -como dije antes- los historiadores más informados y conscientes están llevando a cabo un proceso de reflexión sobre la historicidad del historiador, que les conduce a una conciencia histórica mucho más aguda. Conviene aclarar a este respecto que, contra lo que a veces se piensa, el término "conciencia histórica" no remite a una noción "clara y distinta" (la fantasía racionalista cartesiana, que hace tiempo mostró sus límites, no es capaz tampoco de aportar certidumbre en este punto). En realidad,

178-194; History in Times of Unprecedented Change: A Theory for the 21st Century (London: Bloomsbury, 2019). 
como observó Jörn Rüsen, hay varias modalidades de conciencia histórica. Históricamente es posible distinguir diversas maneras en que los hombres y mujeres occidentales (dejaremos a un lado - pese al enorme interés del asunto - las concepciones sobre el paso del tiempo de otras sociedades ajenas al mundo occidental, para no añadir mayor complejidad al asunto) se han pensado a sí mismos en sus relaciones con su pasado (y a veces también con el futuro, pero en lo que sigue me referiré tan solo a sus relaciones con el pasado). Hablo de "relaciones con el pasado" en un sentido similar al invocado por Herman Paul en su libro Key issues in historical theory, recientemente traducido al español, ${ }^{3}$ donde repasa algunos puntos clave acerca de la teoría de la historia.

Aunque habitualmente nos refiramos a los tres éxtasis del tiempo - pasado, presente y futuro -, para los historiadores normalmente el vector dominante es el pasado en sus relaciones con el presente. Lo que sucede en los últimos tiempos es que la extraordinaria proliferación de pasados, que hoy día difícilmente se conciben como reducidos a un solo pasado, sino que más bien se piensan en su multiplicidad (i. e., como muchos pasados), ha generado una tipología de conciencias históricas. Creo que esa proliferación es un síntoma más de que estamos entrando en una nueva etapa, o mejor dicho estamos cruzando un umbral que nos permite acceder a otra dimensión de la conciencia histórica. La conciencia histórica crítica del período de la Ilustración y la Revolución Francesa dio pie sin duda a un saber muy sesgado por unos valores de carácter moral y político que miraban despectivamente al pasado, al que equiparaban con un nutrido depósito de errores y horrores. El pasado era para ellos antes que nada un interminable lapso temporal de despotismo, ignorancia y superstición. Por eso había que romper a toda costa con ese pasado para, una vez superado, entrar en un nuevo tiempo de libertad, ilustración y predominio de la razón. Tal era en esencia la visión del pasado que nos legó la filosofía de la historia de Voltaire y, tras él, los principales líderes de las revoluciones de finales del XVIII y primeras décadas del XIX. Con anterioridad, la manera tradicional, premoderna, de ver el pasado y de escribir sobre él era, como es sabido, servirse de la escritura de la historia como una colección de exempla destinados el aprendizaje moral y político. Tras esto vendría la visión romántica de los grandes filósofos de la historia del idealismo alemán, en paralelo el desarrollo del método histórico de Ranke y sus seguidores. El advenimiento del historicismo significó una auténtica revolución cultural y, según creo, marcó un cambio sustancial en este punto con respecto a la época de la Ilustración y las primeras revoluciones. Pues bien, a mi juicio durante buena parte del siglo XX y en estas primeras décadas del siglo XXI estamos cruzando un nuevo umbral que nos permite entrar poco a poco en otra dimensión de la conciencia histórica. En la última fase de este nuevo estadio en la que nos encontramos somos ya capaces de historizar la propia historicidad. Nos damos cuenta de que existe una pluralidad de cronotopos y regímenes de historicidad, que uno puede aproximarse al pasado de muchas maneras distintas, que no existe una única conciencia histórica... incluso sospechamos que las ideas de Heidegger acerca de la inmersión del pasado en el futuro, o sobre la temporalidad y la futurición constitutiva de la condición humana, esas ideas, digo, podrían ser propias de un momento histórico particular

\footnotetext{
${ }^{3}$ Herman Paul, La llamada del pasado: claves de la teoría de la historia, (Zaragoza: Instituto Fernando el Católico, 2016).
} 
y concreto que puede ser situado, datado y contextualizado en una determinada tradición. Por tanto, también es posible ahora historizar la idea heideggeriana de historicidad, que durante un tiempo pudo aparecer como un horizonte irrebasable, puesto que se entendía como una categoría trascendental, o al menos como un rasgo antropológico metahistórico. En este sentido sí creo que estamos entrando en una fase muy interesante, llena de incógnitas sobre cómo se pensará la historia y sus variantes de acá a unos pocos años, en relación con una serie de cambios culturales muy marcados (es este un tema amplio, que no puedo desarrollar ahora y me gustaría abordar en un libro que estoy preparando).

Pero, por otra parte, y vuelvo así a la pregunta que usted me hacía, paralelamente a esta profundización de la conciencia de historicidad, en otros sectores mayoritarios de nuestra sociedad observamos un lamentable empobrecimiento o "aplanamiento" de la conciencia histórica. Se trata de un fenómeno preocupante, pues, al mismo tiempo que unos pocos teóricos avanzan en el sentido de enriquecer y complejizar nuestras visiones del pasado, poniendo de relieve la pluralidad que le es inherente, en nuestra época se está produciendo eso que François Hartog llamó hace años presentismo, o Hans Ulrich Gumbrecht "presente amplio" (y que Valdei Lopes de Araujo proponía recientemente redescribir como "actualismo"). El presentismo resulta inquietante porque aplana las tres dimensiones del tiempo y pone a dos de ellas - al pasado y al futuro -, sin matices, al servicio del presente. Varios rasgos de nuestra época, algunos tan positivos como la extraordinaria valoración del patrimonio histórico, hay que leerlos en esa clave. En este sentido, hemos asistido a un verdadero boom de la memoria y en algunos lugares empezamos a constatar abusos y políticas muy inquietantes relacionadas con la obsesión por la llamada "memoria colectiva", consistentes a veces en la aplicación retrospectiva, brutalmente anacrónica, de las normas de corrección política al pasado (supresión de monumentos y obras de arte que no casan con los estándares morales dominantes en la actualidad, etcétera). Si aplicáramos esa lógica de una manera sistemática al pasado en su totalidad, tendríamos que ocultar o destruir la mayoría de las obras de arte: no sólo los monumentos franquistas del Valle de los Caídos, también las pirámides de Egipto, las catedrales medievales o el arte religioso, pues como señaló Walter Benjamin "no hay un monumento de cultura que no sea a la vez un testimonio de barbarie". La historia es lo que es: en ella hay cosas muy buenas y otras muy malas, y a menudo unas y otras están inextricablemente entretejidas, como nos sucede tantas veces a los humanos en todos los terrenos.

Entre los muchos aspectos y manifestaciones de ese miope presentismo hay varios que me parecen especialmente descabellados. Por ejemplo, leía recientemente en la prensa diversas exigencias emanadas de varios grupos militantes para erradicar las estatuas de Colón de las plazas americanas. Creo que los historiadores deberíamos tomarnos en serio ese tipo de propuestas lunáticas de algunos movimientos indigenistas y populistas, y señalar la irracionalidad de un tipo de medidas políticas que, so capa de iconoclasia, fomentan actitudes y mentalidades profundamente antihistóricas. Tales propuestas son sintomáticas de la mentalidad de una época paradójicamente autosatisfecha, convencida de su superioridad moral, en la que muchos parecen pensar que un selecto grupo de quienes ahora habitamos el planeta somos casualmente los seres humanos más listos y virtuosos que 
jamás hayan existido sobre la tierra, y que, en consecuencia, estaríamos autorizados para aplicar retrospectivamente a cualquier sociedad del pasado nuestros criterios, valores y principios, como un lecho de Procusto. Tales actitudes son lo más contrario que cabe imaginar a una conciencia histórica mínimamente desarrollada. Precisamente la conciencia historicista que se desarrolla desde el siglo XIX reconoce que el mundo está en cambio permanente, que las gentes de otras épocas tenían valores, conceptos y maneras de pensar distintos, y que, por el simple hecho de no ser como nosotros, ni estaban locos ni carecían de criterios. Simplemente vivían un tiempo distinto. Su mundo tenía para ellos sentido, tenía su propia legitimidad, y eso hay que respetarlo. Sé que te interesa el acercamiento histórico al tema de la muerte, ${ }^{4}$ y en este sentido me gustaría añadir que el presentismo es profundamente irrespetuoso con los muertos al aplanar el pasado sin ninguna consideración hacia aquellos antepasados nuestros que una vez pisaron la tierra. Para mí, más allá de las reflexiones de Hartog, lo más preocupante del presentismo es esa arrogancia que lleva a muchas gentes a imaginar que nosotros ocupamos el pináculo de los tiempos. Es una forma de "parroquialismo temporal" similar al de quienes creen, sin haber traspasado jamás los estrechos límites de su aldea, que no hay maravilla semejante en el mundo entero. Alguien que vive en el presente con esa estrechez de espíritu y no es consciente de que todas las realidades e instituciones que le rodean poseen profundidad temporal y contienen historia, sencillamente no tiene ojos para captar una dimensión enormemente significativa de su humanidad. Renuncia, además, al contacto con seres humanos y maneras de ver las cosas de otras épocas a través de un conocimiento histórico que, más allá de la utilidad estricta de la historia para el presente, le proporcionaría un saludable sentido de alteridad que le permitiría tomar distancia de lo aparentemente familiar. Por eso, según yo lo veo, el papel de los historiadores es fundamental en nuestros días, porque su trabajo vuelve a dar relieve y color al mundo plano y gris de aquellos que viven instalados en el hoy, y si se interesan ocasionalmente por el ayer lo hacen con afanes presentistas, o sea, por el rendimiento que de ese ayer manipulado pueden extraer para su agenda política.

\section{5) Para finalizar, en su opinión, ¿en qué momento se encuentra la "historia conceptual"?}

JFS.: Formo parte de una red internacional dedicada a trabajar en una serie de temas y de libros acerca de la historia conceptual europea. Es un proyecto en el que llevamos muchos años empeñados y acabamos de publicar un volumen - en el que soy editor junto a Michael Freeden y Willibald Steinmetz - titulado Conceptual History in the European Space. ${ }^{5}$ En ese libro hemos tratado de fijar las coordenadas metodológicas y el plan general para una colección y un proyecto del cual ya se había publicado un libro anterior $^{6}$ y en los próximos meses irán apareciendo varios otros volúmenes. Por otra parte,

\footnotetext{
${ }^{4}$ A este respecto, véase el último artículo del autor de esta entrevista, Daniel Ovalle, "Muerte y larga duración histórica. Hacia el sentido de la muerte en el siglo XXI. Una propuesta teórica para su estudio historiográfico", Revista de Historia y Geografía, 38 (2018): 213-228.

5 Willibald Steinmetz, Michael Freeden y Javier Fernández-Sebastián, Conceptual History in the European Space, (New York-Oxford: Berghahn, 2017).

${ }^{6}$ Pasi Ihalainen, Cornelia Ilie y Kari Palonen, Parliament and Parliamentarism. A Comparative History of a European Concept, (New York-Oxford: Berghahn, 2016).
} 
como seguramente usted ya sabe, desde hace años un numeroso grupo de académicos estamos comprometidos en el proyecto Iberconceptos. Se trata de un proyecto sobre historia conceptual comparada en el ámbito Iberoamericano, que responde a un esquema básicamente nacional, pero tratando de ir más allá. Aunque nuestra primera idea fue emprender una historia verdaderamente Iberoamericana de los conceptos para la cual probablemente el esquema nacional no era lo ideal, tuvimos que conformarnos con esa organización del proyecto, que ha dado origen a numerosas publicaciones, principalmente a una obra de referencia en once volúmenes, ${ }^{7}$ puesto que nos faltaban instrumentos y académicos preparados para abordar los conceptos desde una perspectiva directamente transnacional que abarcase todos los países de América Latina, además de España y Portugal. En todo caso, hicimos lo que era posible hacer en ese momento, y se trató indudablemente de un proyecto pionero, pues si bien había habido ya varios proyectos nacionales (en Alemania, Francia, España, Holanda, Finlandia, etc.) el único proyecto transnacional de historia conceptual, aparte de Iberconceptos, que comenzaba entonces su andadura era uno en Corea del Sur, relativo al Lejano Oriente.

En resumen, yo diría que la semántica histórica - denominación que, junto a la historia de conceptos, incluye el estudio de imágenes, metáforas, símbolos, etc. - está en franca expansión internacional. La asistencia creciente a los congresos que desde el HCG (History of Concepts Group) organizamos cada año (el último se celebró en Oslo, y el de 2018 tendrá lugar en la Universidad de Málaga), la Escuela de Verano de Historia Conceptual, que se celebrará por tercera vez este año en el Colegio de México (con la participación de los grandes nombres de la especialidad en el mundo iberoamericano, incluyendo Guillermo Zermeño y Elías Palti), o el lanzamiento de nuevas revistas (como Ariadna Histórica, Conceptos Históricos e História da Historiografía, en el mundo hispanolusohablante) dan testimonio del auge de la historia conceptual. El momento actual se caracteriza porque estamos siendo capaces de trascender el marco nacional para plantearnos objetivos más ambiciosos, en particular sobre la trayectoria comparada de algunos conceptos fundamentales en el seno de grandes áreas lingüísticas y civilizaciones históricas. Además de los mencionados proyectos pioneros de Iberconceptos y del Asia oriental (que examina la historia de los conceptos en China, Corea y Japón) y del incipiente proyecto europeo, hay un libro reciente, tentativo, sobre historia conceptual en África. ${ }^{8}$ Otra publicación reciente, editada por Magrit Pernau y Dominic Sachsenmaier y que responde al título Global Conceptual History sugiere que poco a poco es posible avanzar hacia una historia conceptual global, que estudie las transferencias culturales e intelectuales entre grandes áreas culturales y lingüísticas. Al fin y al cabo, los conceptos son a un tiempo locales y globales. Atraviesan fronteras, pero al hacerlo experimentan grandes

\footnotetext{
${ }^{7}$ Javier Fernández Sebastián (Dir.) Diccionario político y social del mundo iberoamericano. La era de las revoluciones, 1750-1850, tomo I, (Madrid: CEPC, 2009); Diccionario político y social del mundo iberoamericano. Conceptos políticos fundamentales, 1770-1870, tomo II (10 vols.), (Madrid: CEPC/UPV, 2014). Para una noticia de este proyecto, véase el artículo de Javier Fernández Sebastián y Luis Fernández Torres, "Iberconceptos: Un proyecto de investigación en red. Cuestiones teórico-metodológicas y organizativas", Spagna Contemporánea, XXVII: 51 (2017): 153-175.

${ }^{8}$ Axel Fleisch y Rhiannon Stephen, eds., Doing Conceptual History in Africa, (New York-Oxford: Berghahn, 2016).
} 
modificaciones. Y, como mostró Michel Espagne, transferir un concepto no es simplemente transportarlo, sino más bien metamorfosearlo. Así pues, si ha de volcarse en el molde de la historia global, la historia conceptual deberá incluir en su caja de herramientas instrumentos adecuados no sólo para captar el movimiento de los conceptos en el espacio y en el tiempo, sino también para estudiar a fondo su arraigo en contextos particulares; o, dicho con otras palabras, los fenómenos de recepción.

\section{Perfil académico}

Daniel Ovalle Pastén es doctor en Historia por la Universidad de Chile e investiga temas sobre la teoría de la historia, la conciencia histórica contemporánea, la filosofía de la historia en Paul Ricoeur y la historia de la muerte. Ha sido becario de la Comisión Nacional de Ciencia y Tecnología (CONICYT), del Instituto Francés de Chile e investigador visitante del Fondo Ricoeur (París). Integra la Red de Investigadores de Teoría y Metodología de la Historia (México).

\section{Academic Profile}

Daniel Ovalle Pastén has his $\mathrm{PhD}$ in History at the University of Chile, his research revolving around the theory of history, the historical consciousness, the philosophy of history in Paul Ricoeur, and the history of death. He has been researcher fellow in the National Commission of Scientific and Technological Research of Chile (CONICYT), in the French Institute of Chile, and visiting researcher in the Fonds Ricoeur (París). He takes also part of the Network of Researchers of Theory and Methodology of History (México).

Fecha de recepción: 30 de septiembre de 2019.

Fecha de aceptación: 16 de diciembre de 2019.

Publicación: 31 de diciembre de 2019.

Para citar este artículo: Daniel Ovalle Pastén, "Teoría de la Historia, conciencia histórica e historia conceptual: una conversación con Javier Fernández Sebastián”, Historiografías, 18 (julio-diciembre, 2019): pp. 112-121. 